\title{
Research Article \\ Research on IT English Flipped Classroom Teaching Model Based on SPOC
}

\author{
Lili Liu \\ School of Foreign Languages, Xuchang University, Xuchang 461000, China \\ Correspondence should be addressed to Lili Liu; 1112010@xcu.edu.cn
}

Received 23 April 2021; Revised 21 May 2021; Accepted 31 May 2021; Published 7 June 2021

Academic Editor: Shah Nazir

Copyright (c) 2021 Lili Liu. This is an open access article distributed under the Creative Commons Attribution License, which permits unrestricted use, distribution, and reproduction in any medium, provided the original work is properly cited.

\begin{abstract}
In order to improve the existing problems in the teaching process of IT English courses and improve the quality of IT English, this paper conducts a research on the flipped classroom teaching mode of IT English based on SPOC. The present situation of IT English teaching is analyzed, and the problems existing in the teaching process are also analyzed. On the basis of the above thought, with the support of SPOC platform build IT turn English classroom teaching mode, namely, by setting the course target, learning for class in advance, choose high-quality class, learning information collection, upload the related resources, and do a good job in teaching design complete teacher preparation, and design the specific teaching unit of teaching process, teaching quality evaluation model was constructed. In this way, the teaching quality evaluation results of IT English flipped classroom are obtained, in order to further improve the teaching quality. The experimental results show that the flipped English teaching mode based on SPOC can effectively improve students' performance and increase students' average daily learning time and course satisfaction, and the practical application effect is good.
\end{abstract}

\section{Introduction}

Relevant policies in China propose strengthening the cultivation of international talents. Meanwhile, the outline clearly points out that a group of talents with international vision, familiar with international rules and able to participate in international affairs and international competition, should be cultivated $[1,2]$. With the development of global economic integration, more and more IT companies and II enterprises in China are actively exploring the international market. Therefore, the importance of cultivating IT talents suitable for the international market for China is increasingly prominent [3].

The IT talents required by the international market should not only have solid professional knowledge but also have the ability to communicate professional knowledge in cross-cultural context using English fluently. IT English courses in colleges and universities aim to cultivate students' ability to use foreign language to learn professional knowledge and solve professional problems. Meanwhile, they also focus on improving students' ability to use foreign language to communicate and communicate professional knowledge [4, 5]. IT English is an important course to train students to read and understand the software engineering industry, which can improve students' ability to write English software development documents and oral English communication in the environment of project development, so as to make students more competitive in international software companies after graduation [6].

At present, as far as the status quo of higher education in China is concerned, the IT English teaching in most colleges and universities still adopts the traditional "teacher-oriented" cramming teaching mode, which leads to the general deficiency of students' comprehensive professional English application ability, teamwork ability, and oral expression and communication ability. The main reason for this is that China's current professional English teaching materials have many problems, such as the disconnection between the content of the teaching materials, the teaching mode of the courses, and the actual project development [7]. In this situation, in order to promote the training of international IT talents, the innovative research on the teaching mode and 
method of IT English classroom is a new topic that needs to be studied urgently [8].

In today's international context, how to promote the IT English course teaching method reform and optimization is very urgent and significant, and IT English teaching reform is a new challenge and opportunity. Therefore, this paper studies the flipped classroom teaching mode of IT English based on SPOC in order to improve the teaching quality of IT English and cultivate more IT talents for the society. The following are the key contributions of the proposed study:

(i) To conduct a research on the flipped classroom teaching mode of IT English based on SPOC.

(ii) The present situation of IT English teaching is analyzed, and the problems existing in the teaching process are also analyzed.

(iii) With the support of SPOC platform build IT turn English classroom teaching mode, namely, by setting the course target, learning for class in advance, choose high-quality class, learning information collection, upload the related resources, and do a good job in teaching design complete teacher preparation, and design the specific teaching unit of teaching process, teaching quality evaluation model was constructed.

(iv) The teaching quality evaluation results of IT English flipped classroom are obtained, in order to further improve the teaching quality.

(v) Experimental results of the proposed study show that the flipped English teaching mode based on SPOC can effectively improve students' performance and increase students' average daily learning time and course satisfaction, and the practical application effect is good.

\section{IT English Flipped Classroom Teaching Mode}

2.1. Status Quo of IT English Teaching. The contradiction between the IT market's demand for high-quality talents and the unsatisfactory status quo of IT English teaching requires that the unsatisfactory status quo of IT English teaching be changed and the causes of the unsatisfactory status quo of IT English teaching be analyzed in order to realize the change [9].

(1) There is a big difference in the quality of students and their learning quality is not high.

Students' learning foundation and learning attitude affect the teaching effect of IT English to a great extent. When students come to school, their English level is uneven. In order to facilitate teaching, teachers often set uniform goals in teaching and adopt the same teaching methods for all students. This led to some interesting learning for students who could keep up. However, students who cannot keep up with IT English will hold a fear of difficulties, and the more afraid they become, the more difficult they become, and the result is that they simply give up [10, 11]. In addition, students' learning attitude is not correct. They think that as long as they learn professional courses well, IT English is not important. Of course, some students want to learn IT English well, but they fail to balance the time between IT major and IT English, so that they fail to learn IT English persistently [12].

(2) Teachers do not have advantages in quality, and knowledge and methods are updated slowly.

The IT industry is originally a new industry; there have been no normal colleges to train IT English major teachers, generally computer or English major teachers through advanced study or training to lead the course. Therefore, the basic quality of teachers does not have a great advantage. In addition, with the rapid development of IT industry and the rapid updating of knowledge, teachers are required to update knowledge regularly and in a planned way, but schools and society fail to create a good platform for teachers to update their knowledge [13].

(3) The content of the textbook lags behind the actual development of IT industry English.

A good teaching effect must rely on good teaching materials, and a good set of teaching materials often need a long period of time to be produced, but the IT industry develops rapidly and the industry language vocabulary is updated quickly, so the IT English teaching materials often cannot keep up with the development of the IT industry [14].

\subsection{IT English Flipped Classroom Teaching Mode Based on} SPOC. In 2013, Professor Armando Fox of the University of California at Berkeley proposed SPOC (small private online course). SPOC can not only supplement classroom teaching but also completely replace classroom teaching. It can improve the utilization of classroom and improve students' learning ability and students' participation. By definition, SPOC's small corresponds to MOOC's massive and private corresponds to open. It can be seen that MOOC is mainly aimed at learners from all over the world, while SPOC pays more attention to learners on campus. Flipped classroom refers to readjusting the time inside and outside the classroom and transferring the decision-making power of learning from teachers to students. In this kind of teaching mode, with precious time in the classroom, students can focus more on active project-based learning and jointly study and solve the challenges of localization or globalization and other real-world problems, so as to obtain a deeper understanding. The basic idea of SPOC based IT English flipped classroom teaching mode is to make use of excellent MOOC teaching resources, change the traditional teaching mode, promote blended teaching and student participation, and further improve the teaching quality $[15,16]$.

The main purpose of this paper is to make high-quality MOOC resources effectively used in IT English teaching through SPOC and flipped classroom, so as to improve the teaching efficiency. IT English flipped classroom teaching 
mode includes three parts. The first part is the teacher's preparation before taking this course, including setting course objectives, learning MOOC in advance, selecting high-quality MOOC, collecting learning materials, uploading relevant resources, and doing a good job in teaching design. The second part is the teaching process of a specific teaching unit [17], including before class, in class, and after class, cycle, until the end of the course. The third part is through the construction of teaching quality evaluation model, in order to obtain the evaluation results of IT English flipped classroom teaching mode, in order to improve the existing teaching mode and improve the teaching quality [18].

2.2.1. Teacher Preparation. Before the beginning of the semester course, although the teaching of knowledge points can be replaced by MOOC teaching video, instead of preparing lessons like traditional teaching, teachers need to prepare carefully in advance in the face of new teaching methods. The specific process is shown in Figure 1.

(1) According to the syllabus and students' prior knowledge, teachers set the curriculum objectives and unit teaching objectives.

(2) Learn MOOC in Advance. At present, colleges and universities are not the main body of the construction of MOOC, and teachers are not the creators of the course. Therefore, in order to choose the appropriate MOOC, we need to learn the relevant MOOC courses in advance.

(3) Choose High-Quality MOOC. The existing MOOC resources are very rich, so teachers need to consider many aspects in the selection, such as the teaching objectives of the courses taught, the content of the textbooks used, and the students' knowledge level to select the most suitable MOOC [19].

(4) Collect Learning Materials. Before the class, teachers should record supplementary videos in advance, because the original purpose of MOOC is not just to let the students in the class learn nor is it based on the teaching materials stipulated by our school, so teachers need to be prepared for the parts of teaching videos that do not involve the contents of teaching materials. In addition, we should prepare learning materials for students to read, such as books, websites, and electronic materials, so as to give students more choices of learning resources.

(5) Do a Good Job in Teaching Design. The in class stage is carried out in the classroom environment. But students are the main body of the classroom, and teaching activities and students' learning activities are very different. Teachers need to change the previous teaching design, from the teaching objectives, teaching process, and other aspects of detailed teaching design; the effect of teaching design directly affects the students' complete construction of the course content. The preparation of teachers is the key to flipped teaching in SPOC environment. The five links mentioned in this section require teachers to work hard. The more well-prepared the teachers are in the five links, the smoother the IT English course will be and the better the effect will be [20].

\subsubsection{Implementation of Unit Teaching. IT English course} consists of many teaching units. The so-called unit teaching is a relatively complete unit of knowledge teaching; unit teaching can be a chapter or a section of the course or a knowledge point or a lesson. We divide a unit teaching process into preclass, in class, and after class.

(1) Preclass Stage. The preclass stage is the knowledge imparting stage of this teaching mode. Teachers prepare IT English teaching videos and resources on SPOC platform in advance, and students carry out autonomous learning. In this stage, both teachers and students need to complete many learning links. The specific process of preclass stage is shown in Figure 2.

For IT English teachers, they should first set the teaching objectives of the unit according to the curriculum objectives and syllabus and then compare the selected MOOCS with the teaching materials in detail. If the teacher only publishes similar contents when arranging MOOCS resources but does not match the teaching materials, some students will feel that they do not want to learn or some of the knowledge points in the original MOOCS video cannot be easily understood, which will inevitably reduce students' interest in learning. Therefore, teachers should carefully review the teaching content every week. For the knowledge points not involved in the original MOOCS, teachers should record teaching videos or use other authorized video resources. At the same time, in order to make students better understand the knowledge points, teachers can add some other forms of IT English learning resources (e.g., learning website links, e-books, case materials, etc.) on SPOC platform for students to learn. At the same time, according to the content of the teaching materials, teachers should check and adjust the classroom tests on the original MOOCS and carefully design them. In addition, teachers should participate in the interaction with students before class, try to reply to students as soon as possible, and answer questions online for students. In this process, teachers can also learn the students' mastery of knowledge points, which knowledge is difficult or has been mastered, which students master better, and which students have difficulties in learning. Teachers should make full use of the benefits of discussion. For students, they should first understand the teaching objectives of the unit and then register and log on to SPOC platform to watch the IT English teaching videos of the unit in the selected MOOC, browse various resources, and complete the classroom test according to the requirements of MOOC. It is worth noting that MOOC platform provides online discussion, which can solve the cognitive construction of students' basic knowledge. When students encounter problems that cannot be solved in their study, they can publish topics in the discussion area. Students can help each other to answer them. Generally, some basic knowledge problems can be effectively 


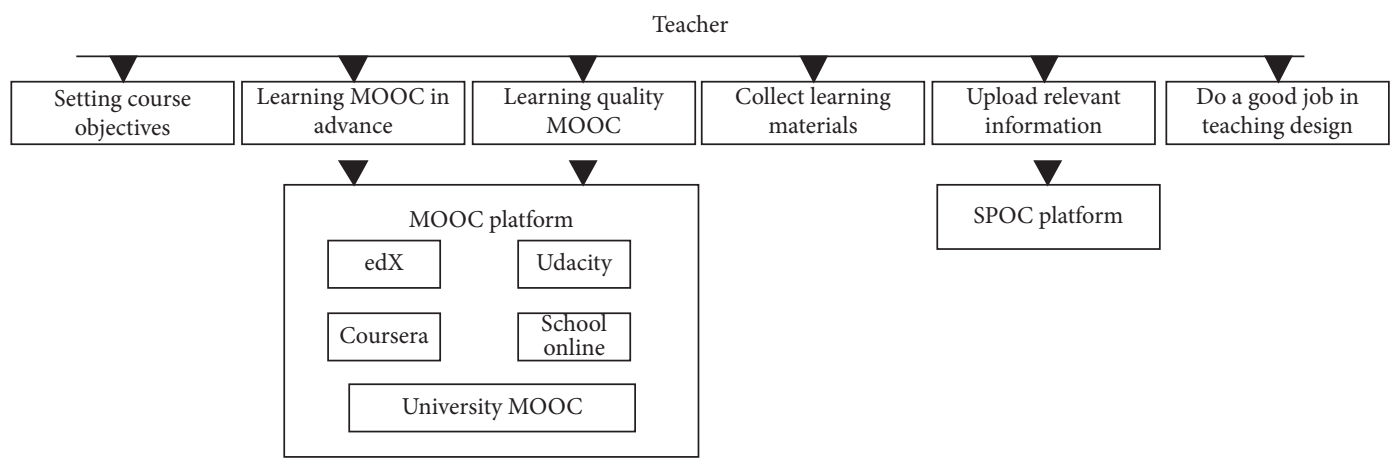

Figure 1: Preparation process of teachers.

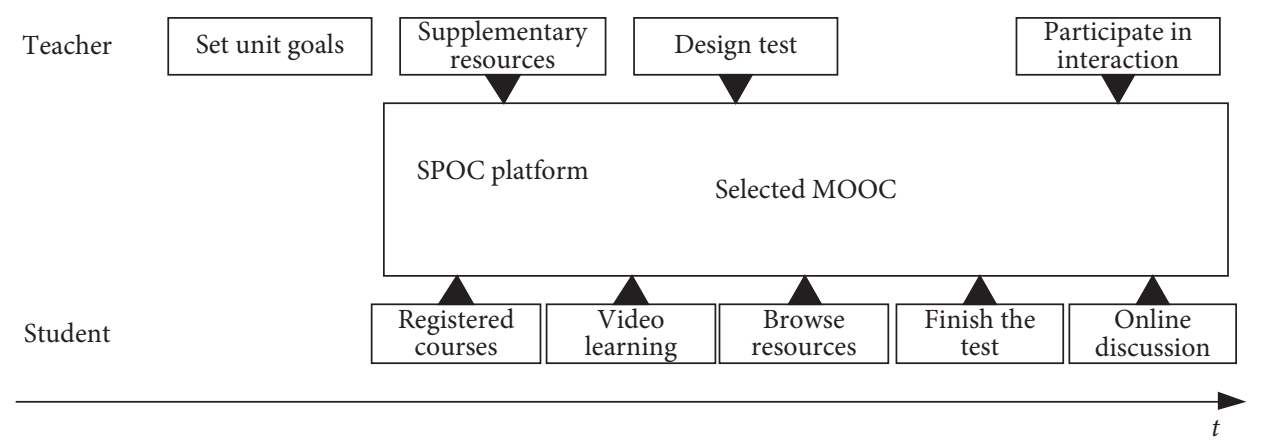

FIgURE 2: Specific process of preclass stage.

solved. In the discussion area, students can also publish their feelings about the learning of this unit. For example, after learning on the platform, they cannot deeply grasp some knowledge points, and they hope that teachers can further explain and discuss them in class. This is also for teachers to better grasp the learning situation of students on the MOOC platform and id conducive to the development of teaching activities.

(2) In Class Stage. The in class stage is the complete knowledge construction stage of IT English curriculum model. In the classroom environment, students should not only master the knowledge completely but also cultivate their abilities in all aspects, such as the ability to solve comprehensive problems independently and creative thinking ability. Therefore, the in class stage is divided into two parts: one part is to discuss the key and difficult points and clarify the knowledge points, so that students can systematically perceive the knowledge points of this class, and construct the knowledge completely, so as to better consolidate the knowledge; the other part includes the activities of raising questions, thinking alone, determining problems, small group discussion, reporting and communication, teachers' puzzles, and summary and evaluation. In this process, we should firmly grasp the knowledge points and improve the ability of comprehensive application. The specific process of the in class stage is shown in Figure 3.

For teachers, first of all, at the beginning of the IT English class, they spend less time with students to discuss the important and difficult points of the content learned in the class, understand the questions that students have not solved and the knowledge points that are difficult to understand, and sort out the content and knowledge points as a whole to help students complete the construction of knowledge. Then most of the rest of the class time is used to cultivate students' comprehensive ability. In order to cultivate students' ability to use knowledge to analyze and solve problems, teachers need to put forward multilevel comprehensive problems. One is slightly more difficult than the general problems, so as to improve students' understanding of unit knowledge. The other is the problem of the comprehensive use of knowledge points, which is used to cultivate students' comprehensive problem-solving ability and improve their high-level thinking. Let the students think independently first. If they cannot solve the problem by themselves, organize the students to discuss these problems in groups. After listening to the students' reports, if the problems have not been effectively solved, the teacher needs to give detailed answers. Finally, according to the classroom situation, the teacher made a summary. For students, first of all, they need to actively participate in the process of discussing important and difficult points and knowledge points with teachers and consult the teachers about the problems they fail to understand in MOOC learning, so as to actively complete the knowledge construction. Then, I will think independently of the questions raised by the teacher and try to solve the problems with the knowledge I have learned in the MOOC. If I cannot solve the problems independently, I will discuss them in groups and actively communicate with my classmates. In the reporting section, students should make a 


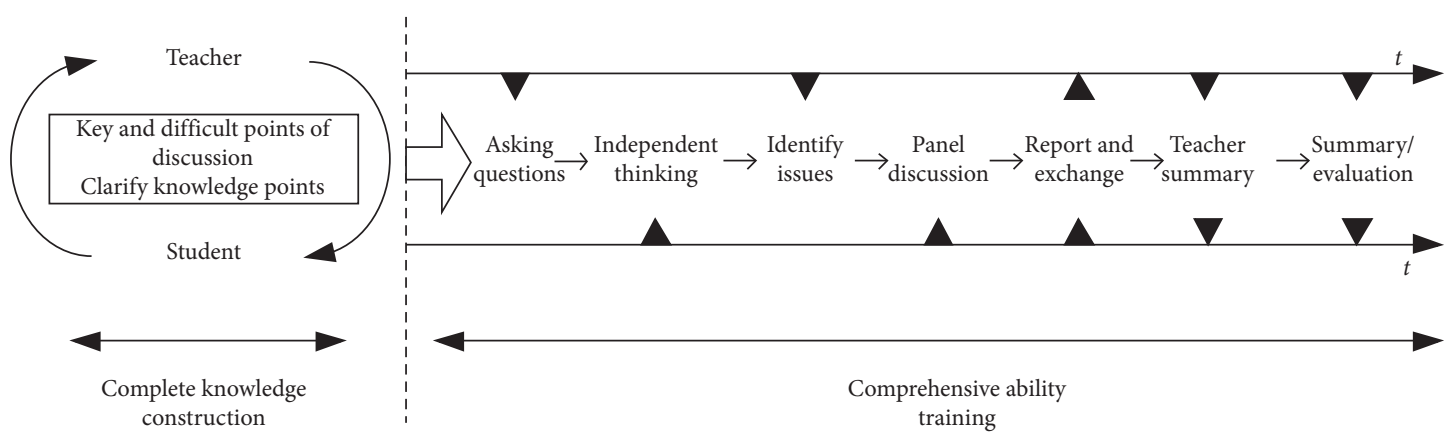

Figure 3: The specific process of the middle class.

report boldly, raise the problems encountered by the group in the discussion process, and listen carefully when the teacher explains the problems and summarizes them, so as to improve their knowledge and ability points.

(3) The After Class Stage. IT is stage after class English teaching mode of study effect test stage, in order to get more accurate results, in addition to the original reference for design of a lesson homework exercises, the teacher on the homework and unit test according to the difficult point problem sets, and knowledge to design to measure whether the overall level of students reached the standard of learning into the next unit. The specific tasks and activities of teachers and students in the after class stage are shown in Figure 4.

For teachers, they should first complete relevant exercises and tests. On this basis, according to the IT English teaching objectives of this unit, homework and unit test questions should be designed from two aspects of knowledge and ability. It is worth noting that, in order to grasp the actual level of students, according to the teaching practice, teachers should appropriately select some topics beyond the teaching objectives when designing homework and unit tests. It is important to point out that students in classroom testing cannot only rely on the class assignments and unit tests they originally desired. This is because the original students who desire classroom teaching are a large number of learners with very different levels of knowledge in all aspects of the world. If you blindly rely on these, you will not be able to accurately understand the real learning situation and effect. Teachers analyze the results of unit tests to give personalized guidance to students who fail to reach the teaching objectives. For students, first of all, they need to complete the homework and unit tests on the SPOC platform, give feedback to teachers to solve the wrong exercises in the homework and tests, and review them accordingly. At the same time, they actively discuss with classmates, help each other, and constantly master and consolidate the knowledge.

2.2.3. Teaching Quality Evaluation Method. The third part is to obtain the teaching quality evaluation results of IT English flipped classroom through the construction of teaching quality evaluation model, in order to improve the existing teaching model and improve the teaching quality. The flipped classroom teaching of IT English is affected by a variety of factors, each of which has different influence on the teaching effect, so IT is difficult to establish an accurate mathematical model. Let the teaching quality evaluation index of IT English flipped classroom be $\left\{x_{1}, x_{2}, \ldots, x_{m}\right\}$. The first step to establish the teaching quality evaluation model of IT English flipped classroom to establish an evaluation index system. A reasonable and scientific evaluation index system can improve the accuracy of teaching quality evaluation, but the teaching quality evaluation is affected by a variety of factors, for example, teaching method, teaching attitude, teaching content, and management and teaching effect, and the evaluation index system of teaching quality was established by referring to relevant literature and research, and then the hierarchical method was adopted to analyze and establish the teaching quality evaluation index system, as shown in Table 1.

When using big data technology to calculate the weight value of teaching quality evaluation index of IT English flipped classroom, Hadoop computing mode is used to calculate the evaluation weight value according to the analytic hierarchy process. First, the judgment matrix is constructed, and the judgment matrix $W$ is expressed as

$$
W=\left(w_{i j}\right) n * n,
$$

where $n$ is the number of horizontal and vertical lines in the matrix, and $w_{i j}$ is the degree coefficient, which is generally as in $[1,10]$. Therefore, for formula (1) above, the degree of influence can be expressed as

$$
w_{j i}=\frac{1}{w_{j i}}, \quad(i, j=1,2, \ldots, n) .
$$

Normalize the data of each column in judgment matrix $W$ to get matrix $W^{\prime}$, add each row of $W^{\prime}$ according to the row to get vector $w$, use the sum product method to find the maximum eigenroot of the vector, and get

$$
\lambda_{\max }=\frac{1}{n} \sum_{i=1}^{n} \frac{W \cdot w^{T}}{w_{i j}},
$$

where $\lambda_{\max }$ is the maximum characteristic root and $T$ is the coefficient of the summation product method. Using the random consistency ratio $\mathrm{CR}$ to judge the consistency of the largest characteristic root, the following calculation can be obtained: 


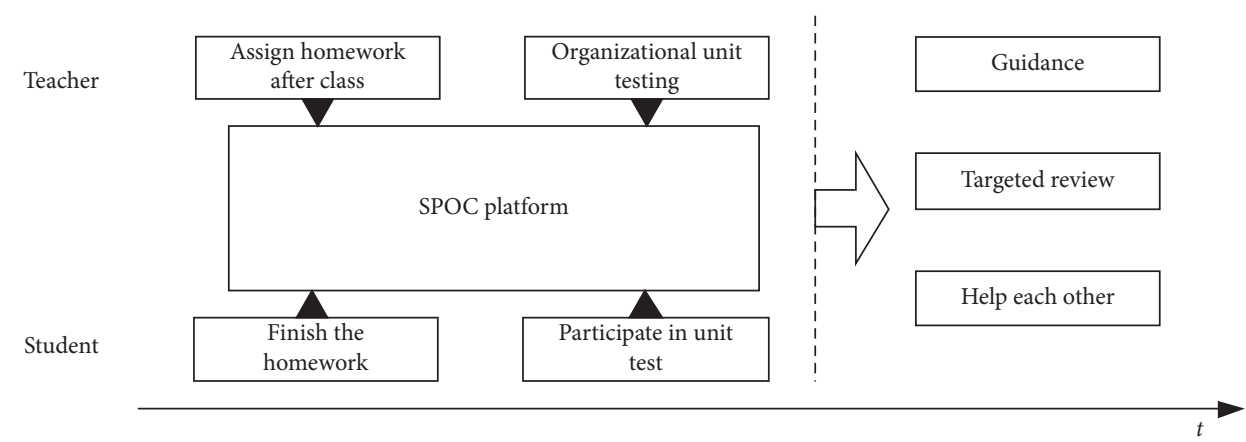

FIGURE 4: Specific tasks and activities of teachers and students in the after class stage.

TABLE 1: Teaching quality evaluation index system.

\begin{tabular}{lc}
\hline Level indicators & Secondary indicators \\
\hline $\begin{array}{l}\text { Teaching } \\
\text { content }\end{array}$ & $\begin{array}{c}\text { Teaching objectives }\left(x_{1}\right) \\
\text { Scientific nature of teaching content }\left(x_{2}\right) \\
\text { Teaching key and difficult points processing } \\
\left(x_{3}\right)\end{array}$ \\
\hline $\begin{array}{l}\text { Teaching } \\
\text { method }\end{array}$ & $\begin{array}{c}\text { Good at heuristic thinking }\left(x_{4}\right) \\
\text { Taking care of personality differences }\left(x_{5}\right) \\
\text { Learning method guidance }\left(x_{6}\right) \\
\text { Teaching tools and means }\left(x_{7}\right)\end{array}$ \\
\hline $\begin{array}{l}\text { Teaching } \\
\text { attitude }\end{array}$ & $\begin{array}{c}\text { Course preparation }\left(x_{8}\right) \\
\text { Degree of engagement }\left(x_{9}\right) \\
\text { Personal quality of teachers }\left(x_{10}\right)\end{array}$ \\
\hline Teaching plan completion $\left(x_{11}\right)$ \\
\hline CR effect \\
Students' mastery of the teaching content $\left(x_{12}\right)$
\end{tabular}

where CI is the consistency index and RI is the average random consistency index. Therefore, the weight value of the final teaching quality evaluation index can be calculated according to the consistency index:

$$
\mathrm{CI}=\frac{\lambda_{\max }-n}{n-1} .
$$

In the above formula, $n$ is the order of the judgment matrix. Formulas (3) and (5) are put together, and the comprehensive random consistency table finally obtains the following: When matrix $W$ meets $\mathrm{CR}<0.1$, the characteristics of the normalized vector can be used as a weighted vector; the final calculation result of formula (2) is the weight of the teaching evaluation index, and the calculation process is repeated to calculate the application-oriented undergraduate teaching evaluation index and its weight value $K=\left\{k_{1}, k_{2}, \ldots, k_{m}\right\}$; then the mathematical expression of teaching quality evaluation model is

$$
y=f\left(k_{1} x_{1}, k_{2} x_{2}, \ldots, k_{m} x_{m}\right) .
$$

In the formula, $f$ represents the evaluation function. The teaching quality evaluation model mentioned above is used to evaluate the teaching quality evaluation of IT English flipped classroom, and the corresponding evaluation results are output, in order to improve the existing problems of IT English flipped classroom teaching model and further improve the teaching quality.

\section{Experimental Design and Result Analysis}

3.1. Experimental Design. In order to verify the effectiveness of the SPOC-based IT English flipped classroom teaching mode, IT needs to be designed. The specific experimental scheme is shown below.

In order to ensure the scientific nature and reliability of the experimental results, the experiment needs to be carried out in a unified experimental environment. The specific experimental environment is shown in Table 2 .

1000 students in a certain university were selected as the research objects, and the research objects were divided into two groups on average. One group used the traditional IT English teaching mode and was designated as experimental group $A$. The other group used the IT English flipped classroom teaching mode proposed in this paper, which was recorded as experimental group $B$, and the changes of various data of students in all groups were recorded and taken as experimental data. The basic data of students are shown in Table 3.

The educational background of students is shown in Table 4.

3.2. Analysis of Experimental Results. Twelve months after the experiment was compared, the average scores of the students in experiment A and experiment B were measured. The results are shown in Table 5.

By analyzing the data in Table 5, it can be seen that the average score of experimental group A presents wavy changes, while the average score of experimental group B presents a steady upward trend. When the experiment lasted for 9 months, the average score of experimental group A reached the maximum of 69.6 , an increase of 3.3 compared with the initial average score of students. However, when the experiment lasted for 12 months, the average score of experimental group $B$ reached the maximum of 81.3 , an increase of 14.5 compared with the initial average score of students, indicating that, compared with experimental group A, the average score of experimental group B improved more significantly. It shows that the flipped English teaching mode based on SPOC can effectively improve students' performance and verifies the effectiveness of this teaching mode.

On the basis of the above experiments, the average daily learning duration of students during the experiment period is compared, and the specific results are shown in Table 6. 
TABle 2: Experimental environment.

\begin{tabular}{lc}
\hline Name & Describe \\
\hline Operating system & Windows7 \\
CPU & Intel Core i5-7300HQ \\
Memory & $32 \mathrm{G}$ \\
Hard disk & $500 \mathrm{~GB}$ \\
Run a memory & $8 \mathrm{G}$ \\
Frequency & $2.1 \mathrm{GHz}$ \\
\hline
\end{tabular}

TABLE 3: Basic data of students.

\begin{tabular}{lcc}
\hline The basic data & Experimental group A & Experimental group B \\
\hline Boys & 236 & 243 \\
The number of girls & 264 & 247 \\
Initial average score of students (full mark is 100) & 66.3 & 66.8 \\
Average learning length of initial day (hours) & 1.59 & 1.52 \\
\hline
\end{tabular}

TABLE 4: Education background of students.

\begin{tabular}{lcc}
\hline Record of formal schooling & Experimental group A & Experimental group B \\
\hline A freshman & 125 & 116 \\
A sophomore & 121 & 135 \\
Junior year & 116 & 98 \\
Senior year & 85 & 111 \\
A graduate student & 35 & 26 \\
The master & 12 & 7 \\
A PhD student & 6 & 7 \\
\hline
\end{tabular}

TABLE 5: Comparison of average scores of students.

\begin{tabular}{lcc}
\hline The experimental time & Experimental group A & Experimental group B \\
\hline 1 month & 67.2 & 67.4 \\
2 months & 66.3 & 68.3 \\
3 months & 65.9 & 69.2 \\
4 months & 68.4 & 70.4 \\
5 months & 69.2 & 72.6 \\
6 months & 66.3 & 73.4 \\
7 months & 67.5 & 74.5 \\
8 months & 68.6 & 76.9 \\
9 months & 69.6 & 78.1 \\
10 months & 66.8 & 79.9 \\
11 months & 67.2 & 80.2 \\
12 months & 67.6 & 81.3 \\
\hline
\end{tabular}

By analyzing the data in Table 6, we can see that the average daily learning time of the students in experimental group A presents a wave like change, while the average daily learning time of the students in experimental group B presents a steady upward trend. When the experiment lasted for 11 months, the average daily learning time of the students in group a reached the maximum of 1.77 hours, which only increased by 0.18 hours compared with the initial average daily learning time. In the 12 months of the experiment, the average daily learning time of the students in the experimental group $B$ reached the maximum of 2.37 hours, which only increased by 0.85 hours compared with the initial average daily learning time, indicating that the average daily learning time of the students in experimental group B increased significantly, indicating that the IT English flipped classroom teaching mode based on SPOC constructed in this paper can effectively stimulate students' interest in learning and improve students' average daily learning time.

Finally, after the results of the experiment, the satisfaction degree of the students in experimental group A and experimental group B with the existing IT English teaching mode was compared. The full score was 100. Each group of students was divided into 10 groups on average, and the satisfaction score of each group was averaged. Student satisfaction scores are shown in Table 7.

By analyzing the data in Table 7 , it can be seen that the average degree of satisfaction of experimental group A is 
TABLE 6: Comparison of average daily learning length of students (hours).

\begin{tabular}{lcc}
\hline Experimental time & Experimental group $A$ & Experimental group $B$ \\
\hline 1 month & 1.61 & 1.59 \\
2 months & 1.72 & 1.63 \\
3 months & 1.69 & 1.68 \\
4 months & 1.73 & 1.69 \\
5 months & 1.68 & 1.72 \\
6 months & 1.75 & 1.75 \\
7 months & 1.74 & 1.81 \\
8 months & 1.71 & 1.85 \\
9 months & 1.69 & 1.96 \\
10 months & 1.68 & 2.17 \\
11 months & 1.77 & 2.25 \\
12 months & 1.72 & 2.37 \\
\hline
\end{tabular}

TABLE 7: Student satisfaction scores.

\begin{tabular}{lcc}
\hline $\begin{array}{l}\text { Experimental } \\
\text { group }\end{array}$ & $\begin{array}{c}\text { Experimental group } \\
\mathrm{A}\end{array}$ & $\begin{array}{c}\text { Experimental group } \\
\mathrm{B}\end{array}$ \\
\hline Team 1 & 67.8 & 92.1 \\
Team 2 & 66.3 & 90.3 \\
Team 3 & 69.5 & 91.5 \\
Team 4 & 67.8 & 92.7 \\
Team 5 & 69.5 & 93.3 \\
Team 6 & 67.7 & 94.1 \\
Team 7 & 69.3 & 93.2 \\
Team 8 & 70.3 & 90.6 \\
Team 9 & 72.4 & 91.3 \\
Team 10 & 70.1 & 95.6 \\
Average & 69.1 & 92.5 \\
\hline
\end{tabular}

69.1, and that of experimental group B is 92.5. The average degree of satisfaction of experimental group $\mathrm{B}$ is 23.4 higher than that of experimental group $\mathrm{A}$, which indicates that students in SPOC based flipped classroom teaching mode can be accepted more, which can effectively stimulate students' interest in learning and improve students' interest in IT English teaching satisfaction of language flipped classroom teaching mode.

\section{Conclusion}

Due to the rapid development of computer network technology, mankind has been brought into the "information age," and the exchanges of science and technology and culture between China and foreign countries have become increasingly frequent. Under the background of globalization, the domestic IT industry is trying to integrate with the world, and a large number of talents who can understand professional technology and have fluent communication with foreign IT professionals are needed. This requires higher vocational colleges to do a good job in IT English teaching, so as to create a solid foundation for students' career development. In short, in recent years, there has been a great demand for talents who are proficient in IT industry knowledge and have good English skills. Meanwhile, with the development of technology, the requirements for these talents are getting higher and higher. In order to improve the quality of IT English teaching, this paper constructs a new flipped classroom teaching mode of IT English based on SPOC and verifies the effectiveness and superiority of this model through experiments. Therefore, this model can effectively improve the effectiveness of IT English teaching and cultivate more outstanding international talents for the development of the IT industry.

\section{Data Availability}

The data used to support the findings of this study are available from the corresponding author upon request.

\section{Conflicts of Interest}

The author declares that there are no conflicts of interest.

\section{References}

[1] F. Zhang, L. L. Dong, C. X. Wang, N. Ye, and Q. He, "Research on project driven it English teaching mode for software engineering majors," Education Teaching Forum, vol. 43, no. 5, pp. 192-194, 2019.

[2] F. Yu, "Research on the innovation of ESP English blended teaching under the background of informatization-taking it English as an example," Campus English, vol. 29, no. 1, pp. 36-37, 2019.

[3] M. Wu, H. H. Wang, J. Zhang, J. Liu, and T. Lu, "Research on blended learning teaching method of it English course software guide," Educational Technology, vol. 25, no. 10, pp. 64-65, 2017.

[4] L. Shao and X. Liu, "The application of ESP in college English teaching-taking it English as an example," Science and Education, vol. 56, no. 4, pp. 192-193, 2019.

[5] F. Zhang, "Task-based IT vocational English project oriented teaching model," University Education, vol. 18, no. 2, pp. 22-24, 2017.

[6] X. M. Gao, "Discussion on it English teaching method," Shanxi Youth, vol. 21, no. 1, pp. 81-87, 2019.

[7] X. Q. Zhang, T. G. Tang, H. Y. Wang, J. R. Zhou, and H. Yang, "“Internet +" research on the innovation and entrepreneurship education mode of IT majors," The Science Education Article Collects, vol. 15, no. 10, pp. 59-61, 2017.

[8] F. Jiang, "On the teaching strategies of IT professional English in higher vocational colleges based on vocational ability training," Times Education, vol. 25, no. 5, pp. 213-214, 2017.

[9] Y. Zhang, "The integration of IT professional English and information professional English education-a case study of 
dalian neusoft information college," Chinese Journal of Education, vol. 48, no. S1, pp. 161-164, 2017.

[10] Z. Yuan, "Discussion on the curriculum reform of IT vocational English based on post demand-taking Wuhan vocational college of software engineering as an example," Journal of Seeking Knowledge Guide, vol. 30, no. 1, pp. 117-118, 2018.

[11] W. J. Cui, "Tourism English teaching mode under modern audio visual education technology," Guangdong Canye, vol. 52, no. 5, pp. 93-94, 2018.

[12] J. Zhu and G. J. Jia, "A study of college English teaching model based on cognitive linguistics," Foreign Language World, vol. 21, no. 3, pp. 30-37, 2018.

[13] L. Cheng, "Research on nursing professional English teaching mode based on content-based instruction idea," Chinese Nursing Research, vol. 32, no. 9, pp. 1449-1451, 2018.

[14] J. N. Shan, H. B. Zhu, B. Pang, Y. W. Li, and J. B. Luan, "Exploration on English teaching modes in TCM universities under humanistic education concept," Western Journal of Traditional Chinese Medicine, vol. 31, no. 10, pp. 40-42, 2018.

[15] S. N. Chu, J. X. Chen, and Y. H. Liu, "Research on the practice of science and trade English translation teaching under the "translation studio" mode," Educational Research, vol. 3, no. 11, pp. 108-109, 2020.

[16] Y. Dou, "Research on teaching mode of electrical engineering English," Transformer, vol. 57, no. 4, pp. 94-99, 2020.

[17] J. G. Liu, "A study on the teaching mode of college English under the background of modern science and technology development," Food Research and Development, vol. 41, no. 21, pp. 258-259, 2020.

[18] X. X. Cui, "Exploration of English teaching mode for electroplating specialty," Electroplating \& Pollution Control, vol. 40, no. 2, pp. 114-115, 2020.

[19] J. Y. Zhang, "Exploration of English teaching mode for electric power specialty," Electric Drive, vol. 49, no. 11, pp. 123-126, 2019.

[20] R. S. Zhou, "English teaching model based on constructivism," Education Review, vol. 25, no. 8, pp. 147-149, 2018. 